\title{
Cementomimetics-constructing a cementum-like biomineralized microlayer via amelogenin-derived peptides
}

\author{
Mustafa Gungormus ${ }^{1, *}$, Ersin E Oren ${ }^{1, *}$, Jeremy A Horst ${ }^{2, *}$, Hanson Fong ${ }^{1}$, Marketa Hnilova ${ }^{1}$, \\ Martha J Somerman ${ }^{3}$, Malcolm L Snead ${ }^{1,4}$, Ram Samudrala ${ }^{1,5}$, Candan Tamerler ${ }^{1}$ and Mehmet Sarikaya ${ }^{1}$
}

Cementum is the outer-, mineralized-tissue covering the tooth root and an essential part of the system of periodontal tissue that anchors the tooth to the bone. Periodontal disease results from the destructive behavior of the host elicited by an infectious biofilm adhering to the tooth root and left untreated, may lead to tooth loss. We describe a novel protocol for identifying peptide sequences from native proteins with the potential to repair damaged dental tissues by controlling hydroxyapatite biomineralization. Using amelogenin as a case study and a bioinformatics scoring matrix, we identified regions within amelogenin that are shared with a set of

hydroxyapatite-binding peptides (HABPs) previously selected by phage display. One 22-amino acid long peptide regions referred to as amelogenin-derived peptide 5 (ADP5) was shown to facilitate cell-free formation of a cementum-like hydroxyapatite mineral layer on demineralized human root dentin that, in turn, supported attachment of periodontal ligament cells in vitro. Our findings have several implications in peptide-assisted mineral formation that mimic biomineralization. By further elaborating the mechanism for protein control over the biomineral formed, we afford new insights into the evolution of protein-mineral interactions. By exploiting small peptide domains of native proteins, our understanding of structure-function relationships of biomineralizing proteins can be extended and these peptides can be utilized to engineer mineral formation. Finally, the cementomimetic layer formed by ADP5 has the potential clinical application to repair diseased root surfaces so as to promote the regeneration of periodontal tissues and thereby reduce the morbidity associated with tooth loss.

International Journal of Oral Science (2012) 4, 69-77; doi:10.1038/ijos.2012.40; published online 29 June 2012

Keywords: amelogenin; amelogenin-derived peptides; bioinformatics; biomineralization; cementomimetics; cementum; demineralization; remineralization

\section{INTRODUCTION}

The distinguishing characteristics of dental bioceramic hard tissues, e.g., enamel, cementum and dentin, are achieved due to the amount of the hydroxyapatite (HAp) crystallites formed, their nano- and microstructural characteristics and their overall architecture. These characteristics originate from the tissue-specific extracellular matrix (ECM) proteins found within each tissue during its development ${ }^{1-5}$ and which act as regulators of nucleation and growth of biological apatite. $^{1-2,6}$ These ECM proteins, therefore, offer great potential in repairing mineralized tissues of the teeth damaged due to carries, trauma or periodontal disease. Periodontal disease is caused by the host's inflammatory reaction to the bacterial biofilms that adhere to the tooth surface $^{7}$ and results in periodontal tissue destruction. It is one of the most prevalent infections of mankind, and left unchecked, will result in the loss of the teeth and surrounding tissue, including bone. ${ }^{7-8}$ The use of dental ECM proteins as therapeutic agents to repair damage caused by such diseases has been limited so far due to technical and financial limitations in the identification, extraction and purification of these proteins. As the therapeutic use of native or recombinant ECM proteins for re-mineralization is not yet viable, research has focused on developing peptide mimics or identifying functional domains within these naturally occurring proteins. ${ }^{8-16}$ As a case study, we used the enamel protein, amelogenin, to identify similarity regions, i.e., domains with similar amino acid sequences, with a set of HAp-binding peptides (HABPs) that we previously experimentally selected. ${ }^{17}$ Amelogenin is expressed during tooth enamel formation and contributes to the hardest and most highly mineralized tissue in the human body by exerting control over the dimension and

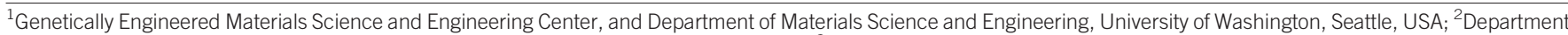

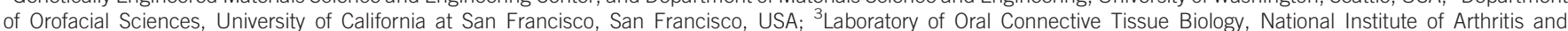

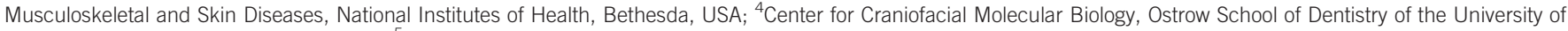
Southern California, Los Angeles, USA and ${ }^{5}$ Department of Microbiology, University of Washington, Seattle, USA

*These authors contributed equally to this work.

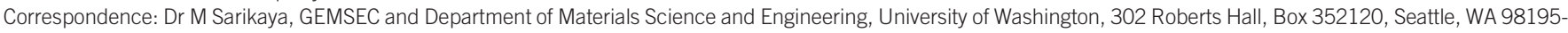
2120, USA

E-mail: sarikaya@u.washington.edu

Received 12 March 2012; accepted 3 May 2012 
directionality of HAp crystals formed within the assembled protein matrix. ${ }^{18-20}$ Although certain regions of amelogenin amino-acid sequence are proposed to interact with calcium phosphate minerals, an extensive mapping of putative crystal interaction or mineral nucleation domains is still lacking. ${ }^{21-22}$ Here, we show that functional peptides can be derived from amelogenin using phage display-selected peptides as a knowledge base and identifying next generations of peptides by bioinformatics. We then show that these peptides can function to direct the cell-free re-mineralization of the tooth root resulting in a cementomimetic (e.g., cementum-like) material and, thus, can contribute to cell-based regeneration of periodontal tissue.

\section{MATERIALS AND METHODS}

\section{Combinatorial selection of peptides}

Selection of the peptides by phage display and the HAp binding and mineralization characterization were carried out as previously described $^{23}$ (see Supplementary Information).

\section{Similarity analysis}

The amino-acid sequences obtained from the combinatorially selected peptides have been used as the data source for our knowledge-based design. Using the methods previously described by Oren and colleagues, ${ }^{17}$ two scoring matrices, HAp12I and HApC7CI, were derived for the peptides selected from the 12- and c7c-phage libraries (New England BioLabs Inc., Ipswich, MA, USA), respectively. The Point Accepted Mutation 250 (PAM 250) was chosen as the seed matrix to optimize the new matrices specific to the selected peptides. The PAM matrix gives substitution probabilities for sequences that experience a certain number of point mutations in every hundred amino acids. Therefore, PAM 250 reflects the probabilities for 250 point mutations for every 100 amino acids. PAM 250 was modified to compensate for the relative abundance of amino acids within the libraries used to select the HABP and for the codon usage of the host organism (Escherichia coli K12 ER2738) used to amplify the phages. To identify the sequence similarities between the selected peptides with the recombinant mouse 180 amino acid long amelogenin (rM180), we divided the rM180 amino-acid sequence into segments with the same length as those from the phage libraries (i.e., 7 or 12 amino acids). Each iteration generated a segment starting from the next amino acid, therefore, creating all possible 7 or 12 amino-acid segment lengths for the whole M180 sequence. Then, each segment was compared with each HABP and was given a similarity score. Once every combination of the HABPs and amelogenin segments were compared, regions that demonstrated high similarity scores against both libraries were overlapped. These coinciding high similarity regions were picked as the putative strong binding regions (see Supplementary Fig. S3). In the same way, coinciding low similarity regions were picked as the putative weak binding regions. These regions were then refined by protein structure prediction, $\mathrm{Ca}^{2+}$ ion-binding domain predictions and meta-functional signature analyses (see Supplementary Information). A schematic description of the design process is shown in Figure 1a.

\section{Peptide synthesis}

rM180 amelogenin was created as described previously. ${ }^{24}$ The amelogenin-derived peptides (ADPs) were synthesized by standard solid phase peptide synthesis technique on Wang resin using F-moc chemistry and HBTU activation. CSBio 336s (CSBio, Menlo Park, CA, USA) automated peptide synthesizer was used for the synthesis. The resulting resin-bound peptides were cleaved and side-chain-deprotected using Reagent $\mathrm{K}$ (trifluoroacetic acid/thioanisole $/ \mathrm{H}_{2} \mathrm{O} /$ phenol/ethanedithiol $\left.(87.5: 5: 5: 2.5)\right)$, and precipitated by cold ether. The crude peptides obtained were purified by reverse phase high performance liquid chromatography up to a $>98 \%$ purity (Gemini $10 \mu \mathrm{C} 18110 \mathrm{~A}$ column). The masses of the purified peptides were checked by mass spectroscopy using a MALDI-TOF mass spectrometer (Bruker Daltonics, Billerica, MA, USA).

\section{Binding analysis via quartz crystal microbalance}

Calcium phosphate-coated quartz crystal microbalance (QCM) electrodes were purchased commercially (Q-Sense, Västra Frölunda, Sweden). The diameter of the crystals and electrodes were 8.8 and $5.0 \mathrm{~mm}$, respectively. The oscillation electronic circuit was a typical Collpits oscillator, which had a buffer amplifier. A $12 \mathrm{~V}$ direct current was applied to the oscillator circuit to drive the crystal, and the frequency was measured with a Hewlett-Packard 53131A frequency counter sampling at $225 \mathrm{~Hz}$ (Universal Counter; Agilent Technologies, Santa Clara, CA, USA). After the crystal was mounted in the cell, they were cleaned and dried with high-purity nitrogen gas and used immediately. To establish a stable baseline, a sufficient amount of buffer solution was introduced into the cell before adding the peptide. The frequency change of the crystal in pure buffer solution was recorded for 30 $60 \mathrm{~min}$. After this step, the desired amount of ADPs was introduced into the cell and the frequency change was recorded continuously.

\section{In vitro solution biomineralization}

An alkaline phosphatase based mineralization model was used as described before to investigate the mineralization behaviors of the peptides $^{22}$ (see Supporting Information for details).

\section{Ex vivo re-mineralization of tooth root}

The cementum-root stock blocks were prepared from single rooted, extracted adult teeth collected at the University of Washington Dental School clinics. No individual identifiers were used and the use of such material complied with the Institutional Review Board guidelines. The teeth were kept in $70 \%$ ethanol solution at $4{ }^{\circ} \mathrm{C}$ until the specimens were prepared. Cylindrical blocks of $4 \mathrm{~mm}$ diameter were cut from the acellular cementum, close to the cementoenamel junction using a trephine bur. The teeth were kept immersed in 70\% ethanolphosphate-buffered saline (PBS) during the cutting to prevent heat damage due to friction. The cut cylindrical blocks were cleaned of contaminating material using PBS and demineralized with 35\% phosphoric acid gel for $10 \mathrm{~s}$. The specimens were stored in $70 \%$ ethanol-PBS solution at $4{ }^{\circ} \mathrm{C}$ until used.

Prior to coating the specimens with the peptide, the previously cut cylindrical blocks were rehydrated and equilibrated for $2 \mathrm{~h}$ in $24 \mathrm{mmol} \cdot \mathrm{L}^{-1}$ Tris-HCl buffer, $\mathrm{pH}$ 7.4. The lyophilized ADP was dissolved in $24 \mathrm{mmol} \cdot \mathrm{L}^{-1}$ Tris-HCl buffer, $\mathrm{pH} 7.4$ to a final concentration of $0.4 \mathrm{mmol} \cdot \mathrm{L}^{-1}$. A $50 \mu \mathrm{L}$ drop of the ADP solution was dropped on top of the specimens and left on the specimen for $10 \mathrm{~min}$ at room temperature in a water saturated chamber to prevent evaporation. Control specimens were identically prepared only by dropping $50 \mu \mathrm{L}$ of buffer alone. At the end of $10 \mathrm{~min}$, the samples were rinsed twice with deionized water. Fluorescent microscopy analysis was performed with fluorescein isothiocyanate-labeled ADP.

Solutions of $9.6 \mathrm{mmol} \cdot \mathrm{L}^{-1} \mathrm{CaCl}_{2}$ and $5.6 \mathrm{mmol} \cdot \mathrm{L}^{-1} \mathrm{PO}_{4}{ }^{3-}$, a mixture of $\mathrm{NaH}_{2} \mathrm{PO}_{4}-\mathrm{H}_{2} \mathrm{O}$ and $\mathrm{Na}_{2} \mathrm{HPO}_{4}-7 \mathrm{H}_{2} \mathrm{O}$, were prepared in $24 \mathrm{mmol} \cdot \mathrm{L}^{-1}$ Tris- $\mathrm{HCl}$ buffer, $\mathrm{pH}$ 7.4. The peptide-coated and noncoated control specimens were placed in $300 \mu \mathrm{L}$ of $\mathrm{Ca}^{2+}$ solution and an equal volume of $\mathrm{PO}_{4}{ }^{3-}$ solution was added to achieve a final 
a

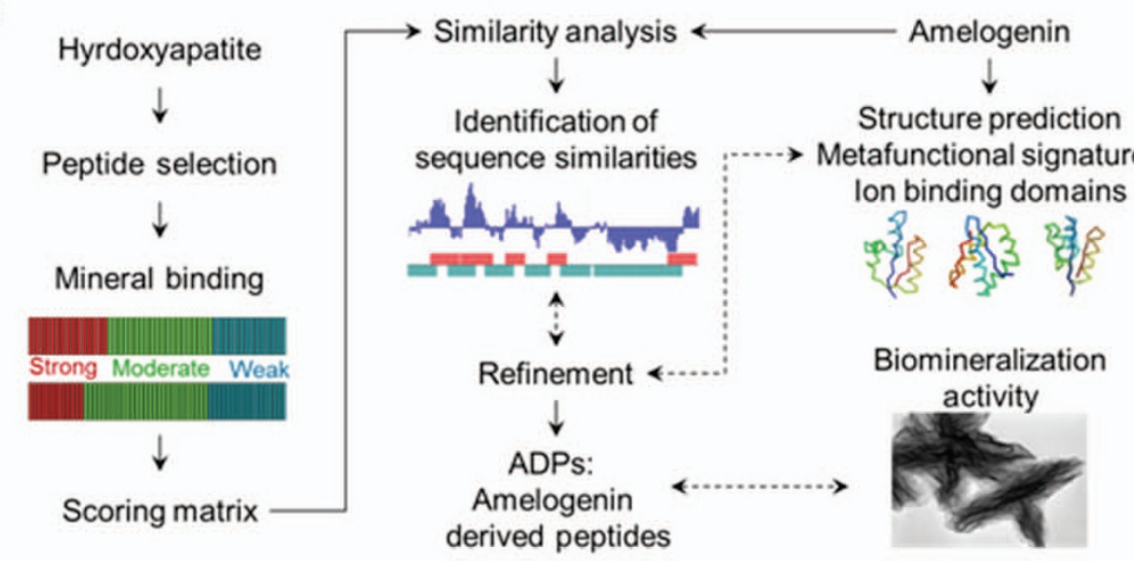

b

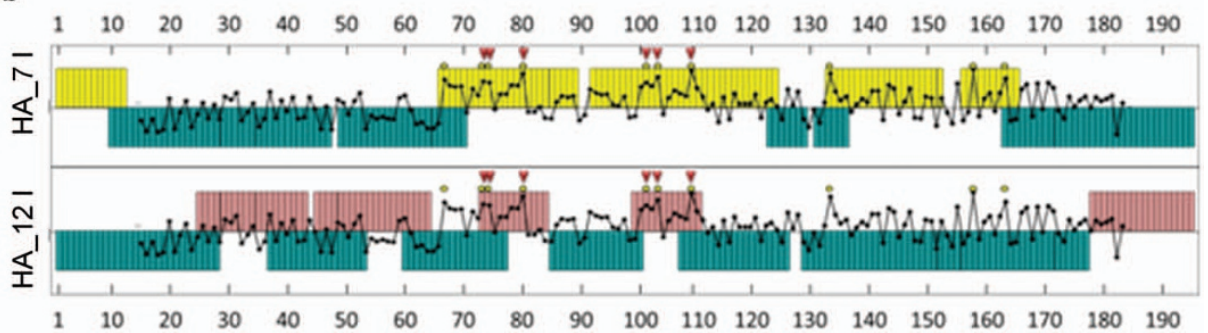

c

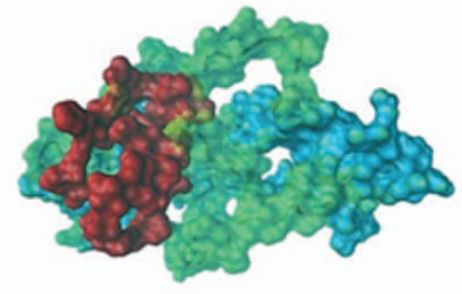

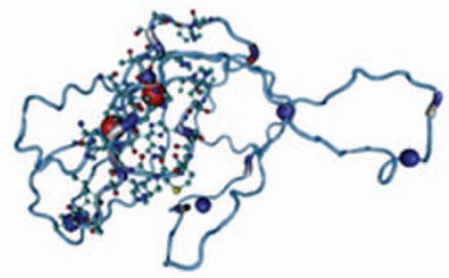

e

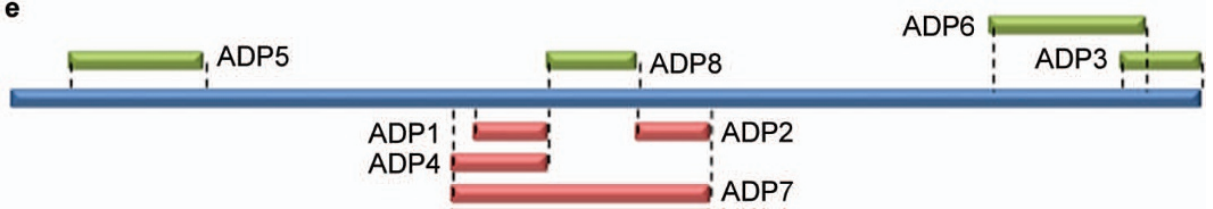

Figure 1 Identification of ADPs. (a) Flowchart showing the design steps for identifying the ADPs. (b) High- and low-similarity amino-acid domains among the rM180 and two experimentally selected HABP sets. Each bar represents one amino acid and the amino-acid domains above the baseline represent the high similarity, while those below represent low similarity regions. The overlapped plot shows the potential calcium ion-binding domains (red arrows). Note that the majority of the highest potential domains coincide with the high-similarity regions (arrow heads). (c) Computationally determined molecular structure for $r$ M180 amelogenin showing position of (folded) ADP7 (red) within rM180 (see Supplementary Information for further details). (d) Positions of the ion-binding domains (blue circles) on rM180. (e) The locations of the ADPs along rM180 (blue) with red colored segments represent the high-similarity regions and green colored segments represent the low-similarity regions. ADP, amelogenin-derived peptide; HABP, hydroxyapatite-binding peptide; rM180, recombinant mouse 180 amino acid long amelogenin.

concentration of $4.8 \mathrm{mmol} \cdot \mathrm{L}^{-1}$ of $\mathrm{Ca}^{2+}$ and $2.8 \mathrm{mmol} \cdot \mathrm{L}^{-1}$ of $\mathrm{PO}_{4}{ }^{3-}$. The specimens were incubated in the mineralization solution for $2 \mathrm{~h}$ at $37^{\circ} \mathrm{C}$ in a water saturated atmosphere, removed from the mineralization solution and rinsed with $24 \mathrm{mmol} \cdot \mathrm{L}^{-1}$ Tris- $\mathrm{HCl}$ buffer, $\mathrm{pH} 7.4$. The specimens were kept in $70 \%$ ethanol solution at $4{ }^{\circ} \mathrm{C}$ until the time of characterization. A schematic explanation of the ex vivo re-mineralization is shown in Figure 2.

\section{Mechanical properties of the cementomimetic layer}

Mechanical properties of the cementomimetic layer were assessed by nanoindentation and qualitative mechanical abrasion tests. The samples were prepared by first infiltrating from the top of the cementomimetic layer with room-temperature-cure epoxy (Allied High Tech, Inc., Rancho Dominguez, CA, USA) to provide a continuous volume for indentation characterization. After the epoxy was cured, the sample was ground and polished to expose the interior in the crosssection of the specimen, then ultra-microtomed to achieve a smooth surface for nanoindentation. Twenty indentations each were taken using an atomic force microscope (attached with a vertical indentor) on mineralized dentin region (indentations were made on intertubular dentin), demineralized dentin regions (adjacent to the cementomimetic layer), and the cementomimetic layer (see Supplementary Fig. S7).

Qualitative mechanical analysis was carried out by ultrasonication and mechanical abrasion. For ultrasonication, specimens were 


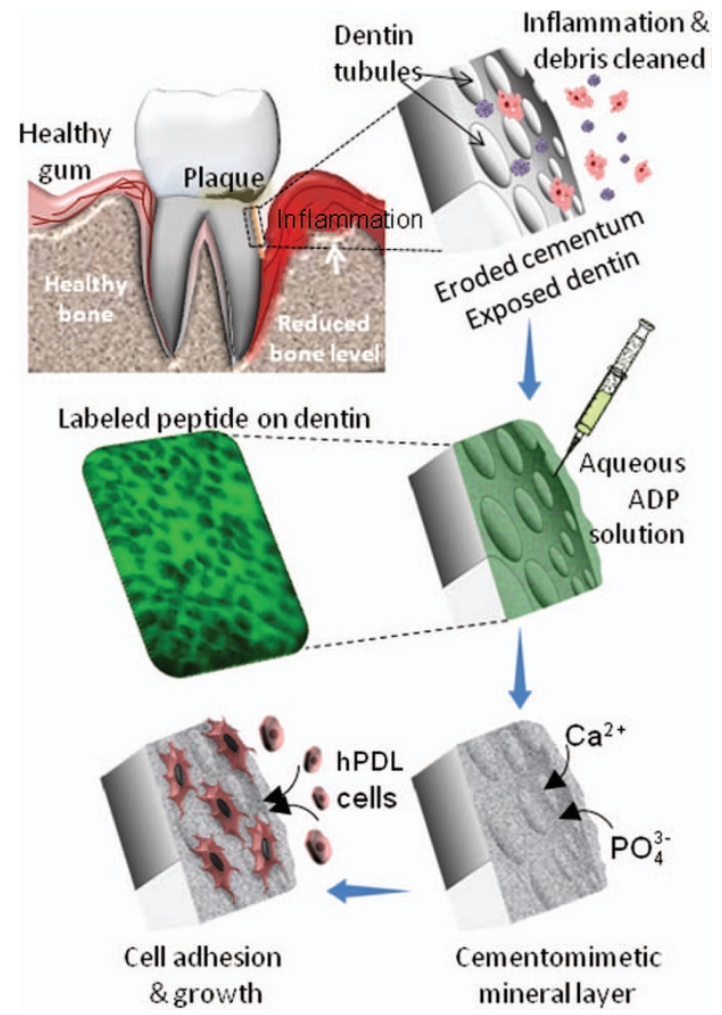

Figure 2 Procedure for in vitro, cell-free synthesis of cementomimetic layer by ADP5 on human root surfaces. Extracted human teeth are cleaned of any contaminating material and cylindrical pieces are cut right below the cement-enamel junction. An aqueous solution of ADP5, the mineralization directing peptide, is applied on the demineralized root surface. The specimen is immersed into a mineralization solution containing calcium and phosphate ions. Cell adhesion and proliferation is investigated on the re-mineralized root surfaces. ADP, amelogenin-derived peptide.

mounted on scanning electron microscopy (SEM) sample mounts and placed in $70 \%$ ethanol in a glass vial. The probe was set to $3 \mathrm{~cm}$ above the specimens and ultrasound energy was applied for $15 \mathrm{~s}$ yielding a total of $10 \mathrm{~J}$. Mechanical abrasion was applied to the same specimens using an electric toothbrush intended for home use (Oral B, series 4000). The specimens and the toothbrush were fixed in position allowing the bristles to be brought into contact with the specimens for $1 \mathrm{~min}$, after which the samples were rinsed with $70 \%$ ethanol and analyzed with SEM.

\section{Cell adhesion and growth assays}

Cell adhesion experiments were accomplished using cultured human periodontal ligament (hPDL) fibroblasts. The cells were maintained in Dulbecco's modified Eagle medium (DMEM) (Life Sciences (formerly Gibco), Grand Island, NY, USA) containing 10\% fetal bovine serum supplemented with 100 units $\cdot \mathrm{mL}^{-1}$ penicillin, $100 \mu \mathrm{g} \cdot \mathrm{mL}^{-1}$ streptomycin and $2 \mathrm{mmol} \cdot \mathrm{L}^{-1}$ glutamine. The cells were used between the seventh and ninth passages. Before starting the cell adhesion assays, the mineralized specimens were taken out of the $70 \%$ ethanol solution and equilibrated in serum-free DMEM for $2 \mathrm{~h}$. The confluent hPDL cells were suspended with $0.05 \%$ trypsin-EDTA and counted using a hemocytometer. The equilibrated tooth specimens were placed in 24-well plates, with four specimens per well performed in triplicates. The suspended hPDL cells were prepared in serum-free DMEM and $3 \times 10^{4}$ cells per well were seeded on top of the specimens. The specimens were incubated with the cells for $2 \mathrm{~h}$ at $37{ }^{\circ} \mathrm{C}$ and $5 \%$ $\mathrm{CO}_{2}$ atmosphere. After $2 \mathrm{~h}$, the specimens were rinsed with the media and cells remaining on the surface were recovered from the surface of the specimen with $0.05 \%$ trypsin-EDTA. The cells so obtained were counted using CyQUANT cell proliferation assay kit (Life Sciences (formerly Invitrogen), Grand Island, NY, USA).

After fixing with $2 \%$ glutaraldehyde in PBS for $10 \mathrm{~min}$, the cells were permeabilized with $0.1 \%$ Triton $\mathrm{X}$ in PBS for 2 min and blocked with $1 \%$ bovine serum albumin for $30 \mathrm{~min}$ and stained with Phalloidin Alexa Fluor 488 (Invitrogen) for fluorescence microscopy observations. The cells were observed and recorded using a TE 300L microscope at an appropriate wavelength and gated filters (Nikon, Tokyo, Japan).

For proliferation assays, hPDL cells were prepared the same way as described above for the cell adhesion assays. The specimens were equilibrated in media and placed in 24 -well plates, four specimens per well and performed in triplicate wells. The suspended hPDL cells were prepared in serum-free DMEM and $3 \times 10^{4}$ cells per well were seeded on top of the specimens. After $24 \mathrm{~h}$, the specimens were rinsed and transferred into new plates to prevent possible contamination of the cells that grow on the bottom of the plate. The cells were maintained in a water-jacketed incubator at $37{ }^{\circ} \mathrm{C}$ in $5 \% \mathrm{CO}_{2}$ saturated to $\mathrm{H}_{2} \mathrm{O}$ and the media was exchanged every $48 \mathrm{~h}$ with DMEM supplemented with $2 \%$ fetal bovine serum. Triplicate samples were terminated after 2-, 6-, 10- and 15-day durations. At the end of each time point, the specimens were taken out of the wells, rinsed with serum-free DMEM, and then with PBS. The cells were recovered from the specimen surface with $0.05 \%$ trypsin-EDTA and counted using CyQUANT cell proliferation assay kit (Invitrogen).

\section{RESULTS}

The critical component in the newly developed cementomimetic mineral construction is HAp-forming peptides that operate as mineral synthesizers and control deposition of a confluent nanostructured HAp layer. The procedure for designing these peptides is schematically described in Figure 1. Using a phage display approach, we combinatorially selected more than 100 HABPs from a 7 -amino acid and a 12-amino acid phage peptide library and characterized their binding affinity to the HAp mineral under near-physiological conditions. ${ }^{22}$ Since not all of the peptides selected have the same affinity to HAp, we next categorized them into three classes: strong-, moderate- and weak-binding peptides. Using bioinformatics classification protocols, ${ }^{23}$ we derived similarity-scoring matrices for both sets of selected septa- and dodeca-peptides. These matrices were used to systematically compare and identify similarity regions, i.e., domains of similar amino-acid sequences between the experimentally selected HABPs and rM180. The comparisons yielded high and low similarity regions along the amelogenin (Figure 1b). By overlapping the high-similarity regions from both libraries, putative crystal binding sequences were identified, referred to as ADPs (Figure $1 \mathrm{~b}$ and $1 \mathrm{e}$ ). The similarity analysis were refined and supported by other computational tools, i.e., structure prediction, meta-functional signature and ion binding domains analyses (Figure 1c and 1d) (see Supplementary Information). Many short amino-acid sequences can be generated by this procedure and each has the potential to be used for specific applications requiring control over HAp formation and growth. The putative HAp interacting regions of amelogenin having the highest similarity, i.e., ADP1, ADP2 and ADP4, were synthesized chemically (see Supplementary Information). For comparison, we also synthesized ADPs corresponding to the previously proposed putative 
Table 1 Amino-acid sequences, physicochemical properties and the dissociation constant $\left(K_{\mathrm{D}}\right)$ of the ADPs used in this study

\begin{tabular}{lcclcc}
\hline ADP & MW & pl & \multicolumn{1}{c}{ Charge } & GRAVY & $K_{\mathrm{D}} /\left(\mu \mathrm{mol} \cdot \mathrm{L}^{-1}\right)$ \\
\hline ADP1 & 1414.60 & 7.10 & 0 & -0.350 & 1395 \\
ADP2 & 1328.40 & 7.00 & 0 & -1.067 & 1611 \\
ADP3 & 1574.70 & 4.94 & $-1(-4,+3)$ & -1.862 & 6397 \\
ADP4 & 1833.00 & 7.16 & 0 & -0.713 & 1431 \\
ADP5 & 2465.60 & 7.16 & $0(-2,+2)$ & -0.959 & 50 \\
ADP6 & 2630.10 & 3.79 & +2 & -0.952 & 6247 \\
ADP7 & 4645.30 & 7.28 & 0 & -0.824 & 1148 \\
ADP8 & 1519.80 & 5.96 & 0 & -0.743 & 314 \\
\hline
\end{tabular}

$A D P$, amelogenin-derived peptide; GRAVY, grand average hydrophaticity; $K_{D}$, dissociation constant; MW, molecular weight; pl, isoelectric point.

mineral-binding regions near the C-terminus (ADP3, ADP6), ${ }^{25-28}$ non-mineral interactive (e.g., low similarity score) regions (ADP5, ADP8) and finally ADP7, a peptide that included ADP1, ADP2 and ADP8 (Figure 1e and Table 1). The HAp-binding affinities of these peptides were examined via QCM and their propensity to control formation of calcium phosphates were carried out via in vitro solution mineralization assays and ex vivo tooth re-mineralization experiments.

\section{Binding analysis via QCM}

The dissociation constants $\left(K_{\mathrm{D}}\right)$ of the peptides were determined. The $K_{\mathrm{D}}$ is an equilibrium constant that represents the concentration necessary to achieve 50\% surface coverage. Experimental binding assays demonstrated that ADP1, ADP2, ADP4 and ADP7 exhibit strong affinity to HAp with $K_{\mathrm{D}}$ values on the order of $1 \mu \mathrm{mol} \cdot \mathrm{L}^{-1}$, as was predicted by the similarity analysis (Figure $3 \mathrm{a}$ and Table 1). Likewise, as predicted, the binding affinities of the ADP3, ADP6, ADP5 and ADP8 were lower, with ADP5 having a significantly lower $K_{\mathrm{D}}\left(50 \mathrm{mmol} \cdot \mathrm{L}^{-1}\right)($ Figure $3 \mathrm{a}$ and Table 1$)$.

\section{In vitro solution biomineralization}

We noted that there were three distinct trends of mineralization among the tested ADPs. The majority of the peptides (ADP1, ADP2, ADP3, ADP4, ADP6 and ADP8) exhibited similar kinetics to the negative control, where no peptide was present. The phage display selected HABP1 and the ADP7 identified in this study exhibited a slow mineralization trend (Figure 3b). Interestingly, full-length rM180 and the ADP5 exhibited a fast mineralization trend, where more than half of the available free $\mathrm{Ca}^{2+}$ was consumed at the end of the $90 \mathrm{~min}$ (Figure 3b) (see Supplementary Fig. S5 for the mineralization trends of all ADPs).

The microstructural and crystallographic analysis of the synthesized minerals via SEM, transmission electron microscopy and X-ray diffraction (XRD) revealed another interesting consequence regarding the relationship between the mineral binding and mineralization activity. Similar to the mineralization kinetics, three distinct trends of mineral morphologies were observed. The majority of the peptides (ADP1, ADP2, ADP3, ADP4, ADP6, ADP8 and HABP1) produced spherulitic particles consistent with the formation of spherical amorphous calcium phosphate and transformation into crystalline phases. $^{29-31}$ The amount of radiating crystalline blade-like particles emanating from the spherulites was slightly higher for ADP1, ADP2, ADP4 and HABP1 (strong binders) compared to ADP3, ADP6 and ADP8 (weak binders) and to the no peptide control, an order indicating that the amorphous to crystalline transformation rates were slightly different (Figure 3c). In the case of rM180 and ADP7, however, a completely different morphology was observed. Needle-like a
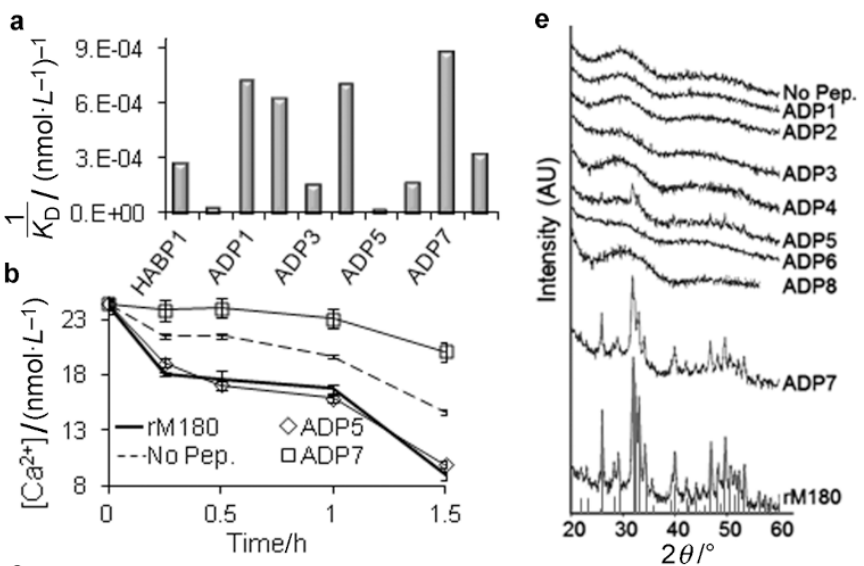

c
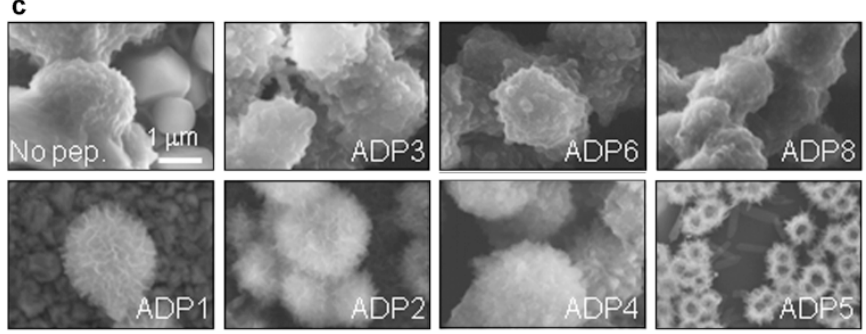

d
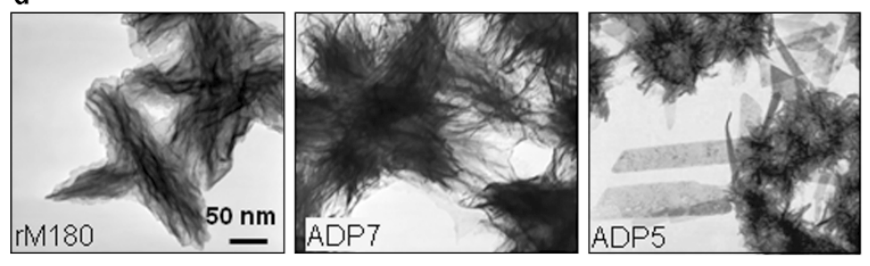

Figure 3 Binding, mineralization, and structural characterization of mineral products of the ADPs. (a) Binding constants, $K_{\mathrm{D}}$, of the ADPs determined by QCM (see Supplementary Information). (b) Calcium consumption rates of mineralization in the presence of ADP5 and ADP7 and rM180. (c) Calcium phosphate minerals formed in solution in the presence of ADPs. (d) The mineral product of ADP7 resembles those formed in the presence of rM180 in solution and these acicular crystallites are consistent with HAp morphology. (e) XRD patterns of the minerals formed by ADPs. Materials formed by ADP7 and amelogenin display the characteristic peaks belonging to the HAp crystal structure, while all minerals formed by other ADPs display weak diffraction peaks, consistent with amorphous, or only loosely crystalline outcomes shown in (c). ADP, amelogenin-derived peptide; HABP, hydroxyapatite-binding peptide; HAp, hydroxyapatite; rM180, recombinant mouse 180 amino acid long amelogenin; XRD, X-ray diffraction.

nanocrystals, organized into bundle-like assemblies, were observed for rM180 and ADP7 (Figure 3d). The bundle-like assemblies appeared to be better organized in the case of rM180, which is consistent with the self-assembly properties of amelogenin and the in vitro mineralization behavior of recombinant amelogenin. ${ }^{24,32-34}$

The particles formed in the presence of ADP5 were much smaller spherulites with a less electron-dense core and smaller radiating crystals (Figure 3c). The smaller particles sizes in the presence of ADP5 may be due to its nucleation-dominate regime, as suggested from the data describing the mineralization kinetics (Supplementary Fig. S3).

The crystallographic analysis via XRD also confirmed that the observed morphological differences were due to different crystal structures. In all cases except rM180 and ADP7, the minerals yielded a broad peak around $2 \theta$ of $25-30^{\circ}$ indicating a poorly crystalline phase (Figure 3e). In the presence of $\mathrm{rM} 180$ and ADP7, however, the XRD patterns consisted of numerous sharp peaks indicative of crystalline 
HAp. The major peaks were observed at $2 \theta=31.8^{\circ}(d=0.281 \mathrm{~nm})$ and $32.1^{\circ}(d=0.278 \mathrm{~nm})$ corresponding to (211) and (300) planes of HAp, respectively.

\section{Ex vivo re-mineralization of the tooth roots}

Human cementum discs were prepared as described in the section on 'Materials and methods' and as illustrated in Figure 2. Fluorescent microscopy analysis with fluorescein-labeled ADP5 showed that the ADP5 readily adsorbs on the demineralized surface of human root
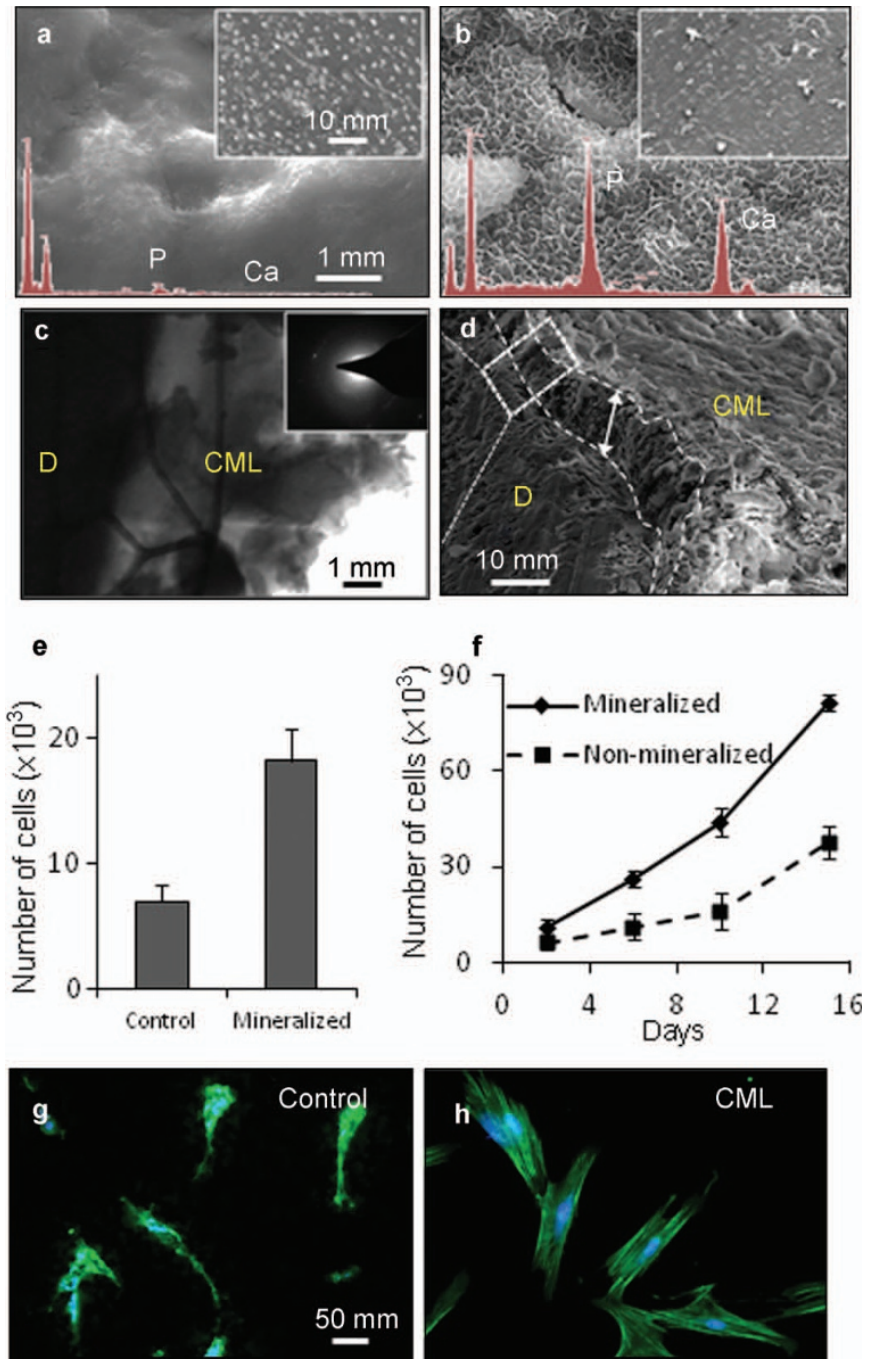

Figure 4 Structural and functional characteristics of the cementomimetic layer formed on the root of human tooth by ADP5. ( $\mathbf{a}$ and $\mathbf{b}$ ) SEM images of the demineralized (a) and (b) ADP5-formed cementomimetic layer revealing uniform nanocrystals with a $\mathrm{Ca} / \mathrm{P}$ ratio of 1.67 obtained from EDX () spectra (insets). (c) TEM images and the electron diffraction pattern of the newly formed cementomimetic mineral layer in cross-section showing HAp crystallites. (d) SEM image of mechanically separated cementomimetic mineral layer displaying uniform thickness of crystallized HAp. (e) Attachment of hPDL cells on control and cementomimetic mineral layer. (f) Proliferation of the hPDL cells on control, uncoated, root stock compared to ADP-induced cementomimetic mineral layer. ( $\mathbf{g}$ and $\mathbf{h}$ ) Fluorescent microscopy image showing F-actin. Cell attachment without formation of organized actin network on control surface (g) is compared to those on ADP-induced cementomimetic mineral layer that reveals a well-organized actin cytoskeleton and lamellapodia (h). EDX, energy dispersive X-ray; $\mathrm{HAp}$, hydroxyapatite; hPDL, human periodontal ligament; SEM, scanning electron microscopy; TEM, transmission electron microscopy. stock cementum and remains on the surface after extensive washing. Since the microscope was calibrated to the emission of the control samples, the background emission was eliminated in both samples. The human samples after cleaning and etching reveal that the expected dentinal tubules characteristic of the dentinoenamel junction, with diameters about $1 \mu \mathrm{m}$, are clearly visible on the fluorescein isothiocyanate-labeled ADP-coated samples (see Supplementary Fig. S6).

ADP5 resulted in a substantial difference in the re-mineralization profiles of the human root stock cementum surface as observed via SEM and energy-dispersive X-ray spectroscopy analysis. At the end of $2 \mathrm{~h}$, no substantial re-mineralization occurred on the control samples consisting of no peptide coating (Figure $4 \mathrm{a}$ ). On the other hand, a continuous layer of mineral covering the whole surface of the specimen was observed on the ADP5-coated specimens (Figure 4b). The morphology of the newly formed mineral was plate-like crystals growing out of the surface of the underlying dentine. Elemental composition analysis by EDS displayed no observable Ca or P peaks from the control sample containing no peptide, where, in contrast, substantial $\mathrm{Ca}$ and $\mathrm{P}$ peaks were observed from the ADP5-coated samples (Figure $4 \mathrm{a}$ and $4 \mathrm{~b}$ inserts, respectively). Both SEM and transmission electron microscopy cross-sectional analysis showed that ADP5 yielded a $10-15 \mu \mathrm{m}$ thick mineral layer that appears to be well integrated with the underlying dentin (Figure $4 \mathrm{c}$ and $4 \mathrm{~d}$ ). Moreover, the thickness of the cell-free biomimetic cementum layer compares well to the thickness of native human acellular cementum.

Mechanical properties of the cementomimetic layer

As shown in Table 2, the cementomimetic mineral layer exhibited comparable elastic modulus and hardness to the native human cementum. ${ }^{35}$ The large standard deviation observed for the cemenotomimetic layer was noted and was likely due to the less homogeneous distribution of mineral than that observed for native mineralized dentin or cementum.

We also tested whether the newly formed mineral layer can survive mechanical stresses produced by ultrasonication and mechanical abrasion (brushing). SEM observations showed that the plate-like morphology of the minerals was somewhat distorted after ultrasonication and brushing. However, as confirmed with energy-dispersive X-ray spectroscopy, the mineral was still attached to the underlying dentin (see Supplementary Fig. S8).

\section{Cell adhesion and growth assays}

Cell attachment assays showed that the hPDL cells attach to the mineralized surfaces more effectively compared to their non-mineralized control surfaces. Quantification of cells recovered after 2-h adhesion period showed that $23.2 \%$ of the cells were adherent on the non-mineralized control surface, whereas $60.6 \%$ of the cells adhered to the biomimetic mineralized surface after $2 \mathrm{~h}$ of incubation (Figure 4e).

Table 2 Mechanical properties of cementomimetic layer as measured by nanoindentation ( $n=20$ indentations)

\begin{tabular}{lcc}
\hline Layer & $E_{\mathrm{r}}$ & $H$ \\
\hline Cementomimetic layer & $19 \pm 7$ & $0.7 \pm 0.5$ \\
Native cementum & $15 \pm 4$ & $0.8 \pm 0.3$ \\
Mineralized dentin & $26 \pm 3$ & $1.0 \pm 0.2$ \\
Demineralized dentin & $5 \pm 3$ & $0.2 \pm 0.2$ \\
\hline
\end{tabular}

$E_{\mathrm{r}}$, Young's modulus; $H$, hardness. 
Proliferation assays showed that the hPDL cells grow more efficiently on the biomimetic mineralized surfaces compared to nonmineralized control surfaces. At the end of 15 days, hPDL cells have reached more than twice the number cells on the biomimetic mineralized surfaces compared to the control surface (Figure $4 \mathrm{f}$ ). These data suggest that the cementomimetic mineral layer provides a favorable environment for the hPDL cells to attach and to proliferate. Fluorescence imaging showed that, after initial adhesion, the cells organize their cytoskeleton on the mineral layer better (Figure 4h) than the same cells growing on control surfaces (Figure $4 \mathrm{~g}$ ).

\section{DISCUSSION}

The quantitative diffraction and microscopy analyses of the minerals produced by the ADPs revealed that, among the designed peptides, only ADP7, the longest of the similarity regions, and native rM180 produced needle-like, crystalline HAp particles, while the others formed crystalline spherulite particles (Figure $3 c-3 e$ ). Interestingly, the N-terminal ADP5, which revealed no binding affinity to HAp, exerted a kinetic control over calcium phosphate nucleation at a level similar to full-length rM180 amelogenin protein (Figure 3b). The fact that the ADP5 did not demonstrate a high affinity to HAp indicates that control over nucleation is governed by interactions with precursor ions. As suggested previously in the literature, these data indicate that the amelogenin protein may be divisible into individual domains that exert separate control over calcium phosphate crystal nucleation, growth and morphogenesis. ${ }^{36-40}$

Taken together, these data indicate that the strong binding affinity by a peptide to its mineral substrate does not necessarily always translate into mineralization directing activity. The fact that the ADP5 showed no significant binding affinity towards HAp but resulted in faster kinetics implies that the ADP5 might be interacting with the soluble precursor ions rather than the mineral surface. The two adjacent pairs of oppositely charged residues at positions 9-10 and 19-20 within ADP5 may be responsible for attracting soluble $\mathrm{Ca}^{2+}$ and $\mathrm{PO}_{4}{ }^{3-}$ and creating an increased local supersaturation and, thereby, decreasing the nucleation barrier. In contrast, the strong interaction between ADP7 and the mineral surface indicates that a change in the mineral-solution interfacial energy is responsible for the observed mineralization behavior. It has been reported that biomolecules, such as citrate, can alter the interfacial energy of kinetically favorable metastable calcium phosphate phases and trigger the phase transformation towards thermodynamically favorable HAp. ${ }^{41-42}$ A similar effect may be responsible, due to the relatively high affinity of ADP7 to the mineral surface. Binding of a peptide on a crystal surface is determined by both the conformation (side chain availability) of the peptide and the atomic configuration of the crystal at the binding interface. ${ }^{43-45} \mathrm{We}$ speculate that the formation of HAp instead of other metastable CaP phases, such as amorphous calcium phosphate, octacalcium phosphate or tricalcium phosphate, in the presence of ADP7, is due to a specific conformation of the peptide and the arrangement of $\mathrm{Ca}$ and $\mathrm{P}$ sites on the crystal surface that maximizes the binding energy and, in turn, reduces the interfacial energy barrier required to overcome phase transformation.

The binding and biomineralization behaviors of ADP5, ADP7 and rM180 imply an interesting mechanism for amelogenin-mediated mineralization during the formation of enamel. The fact that two different ADPs emulate different aspects of the mother protein brings up the question whether these peptides might be different functional regions within amelogenin. ${ }^{37}$ Namely, ADP5 may be the region responsible for increased mineralization kinetics through increasing local supersaturation and ADP7 may be the region responsible for favoring the phase transformation towards HAp through altering the interfacial energy. However, the answers to these questions are the focus of another ongoing study.

The range of characteristics exhibited by these individual ADPs represents potential molecular agents to consider for engineering and biomedical applications involving hard tissue repair and replacement where specific control features for the mineral phase are desired. Peptide-assisted re-mineralization of dental tissue defects offers a significant potential for clinical use. Towards this end, we asked whether or not the biomimetic cementum-like mineral layer has a favorable effect on cell behavior in vitro. Cultured hPDL were selected for investigation since these are the predominant cell types that root surfaces are exposed to in vivo, and further, these cells, when appropriately triggered, can carry on important functions in the repair and regeneration of periodontal tissues. ${ }^{46-50}$ Cell adhesion and cell proliferation assays, performed on the surface of ADP5-mediated cementum-like tooth material in the absence of serum-derived factors, showed that the nanostructured mineral layer favors both the adhesion and proliferation of cells derived from the periodontium (Figure $4 \mathrm{e}$ and $4 \mathrm{f}$ ). We are presently refining conditions for generating the cementomimetic layer seeking to engineer further improvements to attachment and proliferation so as to improve the regenerative competency of this material.

In conclusion, the work described here has several significant implications in peptide-assisted biomineralization. First, we describe a new protocol for identifying peptide sequences from among native proteins associated with HAp-containing tissues that are critical to their control over biomineralization. A similar analysis of extracellular matrix proteins associated with biominerals formed by unicellular organisms (e.g., magnetotactic bacteria), invertebrate (sponges, mollusks) and vertebrate animals can reveal other unique amino-acid domains that regulate the mineral formation and growth for each of their variety of inorganic compounds (magnetite, silica and calcium carbonate polymorphs). ${ }^{51}$ Biomineralization is fundamental to many living organisms and the range of precipitated minerals reflects the elements of the periodic table. Elaborating the mechanism for protein control over the biominerals formed in these systems will afford new insights into the evolution of protein-mineral interactions. ${ }^{52}$ In the case of enamel, amelogenin is a member of the class of intrinsically disorganized proteins. ${ }^{53}$ By restricting a structural analysis to a small domain of a larger protein, such as that defined by ADP5, it is possible to expand our understanding of structure-function relationships, portending the capacity to decipher a relationship between a peptide and a chemical precipitate, and then to use such information for their practical utility to engineer material formation technologies (e.g., bionanomanufacturing). Secondly, as demonstrated in this study, strong binding affinity of a peptide to an inorganic solid is not necessarily an indication of its mineral formation capability. Thirdly, the cementomimetic layer formed by ADP5 has a clinical application potential to repair diseased root surfaces, both those caused by caries and periodontal disease, and to promote regeneration of periodontal tissue, reducing the morbidity associated with tooth loss.

\section{AUTHOR CONTRIBUTIONS}

MG, MH and CT identified the combinatorial selected peptides; MG carried out the binding studies with QCM, carried out XRD and cell culture experiments and contributed to the content of the manuscript; MG and HF carried out mineralization and microscopy studies; M 
Sarikaya, EEO, JAH and RS designed the amelogenin derived peptide sequences. EEO, JAH, and RS performed bioinformatics and computational modeling of amelogenin; RS, JAH and EEO identified metafunctional signatures and ion-binding domains; MLS provided mouse amelogenin, contributed to the dissection of amelogenin domains and functions and contributed to the content of the manuscript; CT supervised $\mathrm{MG}, \mathrm{HF}$ and $\mathrm{MH}$, contributed to the creation of genetically engineered peptides and contributed to the content of the manuscript; MJS provided the cells, directed the research toward cementum regeneration and contributed to the content of the manuscript; M Sarikaya proposed to investigate similarity regions along amelogenin using combinatorial library-selected peptide sequences towards HAp biomineralization, directed the research, and contributed to the content of the manuscript.

\section{ACKNOWLEDGEMENTS}

The research was mainly supported by NSF-MRSEC (DMR\# 0520567) at the University of Washington (MG, MH, HF, RS, EEO, CT and MS); by NIH, National Institute of Dental and Craniofacial Research grant DE13045 (MLS), and grant DE15109 to MJS (The studies described here were completed while MJS was at the University of Washington); JAH was supported by the University of Washington, Warren G. Magnuson Scholars Award and the NIH, National Institute of Dental and Craniofacial Research Ruth L. Kirschstein Individual pre-doctoral dental scientist fellowship, 5F30DE01752. Experiments and computational studies were carried at GEMSEC's Shared Experimental and Computational Facilities at the University of Washington, a part of MRSECMaterials Research Facilities Network. The authors thank Dr B R Wilson for technical help in QCM studies.

1 Lowenstam HA, Weiner S. On biomineralization. New York: Oxford University Press, 1989.

2 Mann S. Biomineralization: principles and concepts in bioinorganic materials chemistry. New York: Oxford University, 2001.

3 Begue-Kirn C, Krebsbach PH, Bartlett JD et al. Dentin sialoprotein, dentin phosphoprotein, enamelysin and ameloblastin: tooth-specific molecules that are distinctively expressed during murine dental differentiation. Eur J Oral Sci 1998; 106(5): 963-970.

4 DSouza RN, Cavender A, Sunavala G et al. Gene expression patterns of murine dentin matrix protein 1 (Dmp1) and dentin sialophosphoprotein (DSPP) suggest distinct developmental functions in vivo. J Bone Miner Res 1997; 12(12): 20402049.

5 Gajjeraman S, Narayanan K, Hao JJ et al. Matrix macromolecules in hard tissues control the nucleation and hierarchical assembly of hydroxyapatite. J Biol Chem 2007; 282(2): 1193-1204.

6 Cöelfen H, Antonietti M. Mesocrystals and nonclassical crystallization. New York: John Wiley \& Sons, 2008.

7 Taubman MA, Valverde P, Han XZ et al. Immune response: the key to bone resorption in periodontal disease. J Periodontol 2005; 76(11): 2033-2041.

8 Goldberg HA, Warner KJ, Li MC et al. Binding of bone sialoprotein, osteopontin and synthetic polypeptides to hydroxyapatite. Connect Tissue Res 2001; 42(1): 25-37.

9 Gu LS, Kim YK, Liu Y et al. Immobilization of a phosphonated analog of matrix phosphoproteins within cross-linked collagen as a templating mechanism for biomimetic mineralization. Acta Biomater 2011; 7(1): 268-277.

$10 \mathrm{Kim} \mathrm{J}$, Arola DD, Gu LS et al. Functional biomimetic analogs help remineralize apatitedepleted demineralized resin-infiltrated dentin via a bottom-up approach. Acta Biomater 2010; 6(7): 2740-2750.

11 Capriotti LA, Beebe TP, Schneider JP. Hydroxyapatite surface-induced peptide folding. J Am Chem Soc 2007; 129(16): 5281-5287.

12 Taller A, Grohe B, Rogers KA et al. Specific adsorption of osteopontin and synthetic polypeptides to calcium oxalate monohydrate crystals. Biophys J 2007; 93(5): 17681777.

13 Wazen RM, Tye CE, Goldberg HA et al. In vivo functional analysis of polyglutamic acid domains in recombinant bone sialoprotein. J Histochem Cytochem 2007; 55(1): 3542.

14 Zhang SF, Gangal G, Uludag H. 'Magic bullets' for bone diseases: progress in rational design of bone-seeking medicinal agents. Chem Soc Rev 2007; 36(3): 507-531.

15 Tye CE, Rattray KR, Warner KJ et al. Delineation of the hydroxyapatite-nucleating domains of bone sialoprotein. J Biol Chem 2003; 278(10): 7949-7955.
16 Pampena DA, Robertson KA, Litvinova $\mathrm{O}$ et al. Inhibition of hydroxyapatite formation by osteopontin phosphopeptides. Biochem J 2004; 378(Pt 3): 1083-1087.

17 Oren EE, Tamerler C, Sahin D et al. A novel knowledge-based approach to design inorganic-binding peptides. Bioinformatics 2007; 23(21): 2816-2822.

18 Snead ML, Zhu DH, Lei YP et al. Protein self-assembly creates a nanoscale device for biomineralization. Mater Sci Eng C 2006; 26(8): 1296-1300.

19 Du C, Falini G, Fermani S et al. Supramolecular assembly of amelogenin nanospheres into birefringent microribbons. Science 2005; 307(5714): 1450-1454

20 Bartlett JD, Ganss B, Goldberg M et al. Protein-protein interactions of the developing enamel matrix. Curr Top Dev Biol 2006; 74: 57-115.

21 lijima M, Moradian-Oldak J. Interactions of amelogenins with octacalcium phosphate crystal faces are dose dependent. Calcif Tissue Int 2004; 74(6): 522-531.

22 Fan D, lijima M, Bromley KM et al. The cooperation of enamelin and amelogenin in controlling octacalcium phosphate crystal morphology. Cells Tissues Organs 2011 194(2/3/4): 194-198.

23 Gungormus $\mathrm{M}$, Fong $\mathrm{H}$, Kim IW et al. Regulation of in vitro calcium phosphate mineralization by combinatorially selected hydroxyapatite-binding peptides. Biomacromolecules 2008; 9(3): 966-973.

24 Moradian-Oldak J, Paine ML, Lei YP et al. Self-assembly properties of recombinant engineered amelogenin proteins analyzed by dynamic light scattering and atomic force microscopy. J Struct Biol 2000; 131(1): 27-37.

25 Pugach MK, Li Y, Suggs $C$ et al. The amelogenin C-terminus is required for enamel development. J Dent Res 2010; 89(2): 165-169.

26 Friddle RW, Battle K, Trubetskoy V et al. Single-molecule determination of the facespecific adsorption of amelogenin's C-terminus on hydroxyapatite. Angew Chem Int Ed 2011; 50(33): 7541-7545.

27 Shaw WJ, Campbell AA, Paine ML et al. The $\mathrm{COOH}$ terminus of the amelogenin, LRAP, is oriented next to the hydroxyapatite surface. J Biol Chem 2004; 279(39): 4026340266.

28 Aoba T, Moreno EC, Kresak M et al. Possible roles of partial sequences at N- and Ctermini of amelogenin in protein-enamel mineral interaction. J Dent Res 1989; 68(9): 1331-1336.

29 Arys A, Jedwab J, Pireaux JJ et al. Brushite in the pulp of primary molars. J Oral Pathol Med 1989; 18(7): 371-376.

30 Kodaka T, Hirayama A, Mori R et al. Spherulitic brushite stones in the dental pulp of a cow. J Electron Microsc 1998; 47(1): 57-65.

31 Achilles W, Jockel U, Schaper A et al. In-vitro formation of urinary stones-generation of spherulites of calcium-phosphate in gel and overgrowth with calcium-oxalate using a new flow model of crystallization. Scann Microsc 1995; 9(2): 577-586.

32 Margolis HC, Beniash E, Fowler CE. Role of macromolecular assembly of enamel matrix proteins in enamel formation. J Dent Res 2006; 85(9): 775-793.

33 Beniash E, Simmer JP, Margolis HC. The effect of recombinant mouse amelogenins on the formation and organization of hydroxyapatite crystals in vitro. J Struct Biol 2005; 149(2): 182-190.

34 Fan Y, Sun Z, Moradian-Oldak J. Controlled remineralization of enamel in the presence of amelogenin and fluoride. Biomaterials 2009; 30(4): 478-483.

35 Ho SP, Yu B, Yun W et al. Structure, chemical composition and mechanical properties of human and rat cementum and its interface with root dentin. Acta Biomater 2009; 5(2): 707-718

36 Moradian-Oldak J, Paine ML, Lei YP et al. Carboxy- and amino-terminal domains of amelogenin are involved in the supramolecular self-assembly. J Dent Res 2000; 79. 513-513.

37 Paine ML, Luo W, Zhu DH et al. Functional domains for amelogenin revealed by compound genetic defects. J Bone Miner Res 2003; 18(3): 466-472.

38 Snead ML. Amelogenin protein exhibits a modular design: implications for form and function. Connect Tissue Res 2003; 44: 47-51.

39 Dunglas C, Septier D, Paine ML et al. Ultrastructure of forming enamel in mouse bearing a transgene that disrupt amelogenin assembly domains. J Dent Res 2001 80(4): 1278-1278.

40 Le Norcy E, Kwak SY, Wiedemann-Bidlack FB et al. Potential role of the amelogenin Nterminus in the regulation of calcium phosphate formation in vitro. Cells Tissues Organs $2011 ; 194(2 / 3 / 4): 188-193$.

41 Qiu SR, Wierzbicki A, Orme CA et al. Molecular modulation of calcium oxalate crystallization by osteopontin and citrate. Proc Natl Acad Sci U S A 2004; 101(7): 1811-1815.

42 Jiang WG, Chu XB, Wang B et al. Biomimetically triggered inorganic crystal transformation by biomolecules: a new understanding of biomineralization. J Phys Chem B 2009; 113(31): 10838-10844.

43 Elangovan S, Margolis HC, Oppenheim FG et al. Conformational changes in salivary proline-rich protein 1 upon adsorption to calcium phosphate crystalsle. Langmuir 2007; 23(22): 11200-11205

44 Masica DL, Gray JJ. Solution- and adsorbed-state structural ensembles predicted for the statherin-hydroxyapatite system. Biophys J 2009; 96(8): 3082-3091.

45 So CR, Tamerler C, Sarikaya M. Adsorption, diffusion, and self-assembly of an engineered gold-binding peptide on $\mathrm{Au}(111)$ investigated by atomic force microscopy. Angew Chem Int Ed 2009; 48(28): 5174-5177.

46 Nagatomo K, Komaki M, Sekiya I et al. Stem cell properties of human periodontal ligament cells. J Periodontol Res 2006; 41(4): 303-310.

47 Seo BM, Miura M, Gronthos S et al. Investigation of multipotent postnatal stem cells from human periodontal ligament. Lancet 2004; 364(9429): 149-155.

48 Seo BM, Miura M, Sonoyama W et al. Recovery of stem cells from cryopreserved periodontal ligament. J Dent Res 2005; 84(10): 907-912. 
49 Gay IC, Chen S, MacDougall M. Isolation and characterization of multipotent human periodontal ligament stem cells. Orthod Craniofac Res 2007; 10(3): 149160

50 Ivanovski S, Gronthos S, Shi S et al. Stem cells in the periodontal ligament. Oral Diseases 2006; 12(4): 358-363.

51 Sarikaya M, Aksay IA. Biomimetics: design and processing of materials. Woodburry: NYAIP Press, 1995.

52 Laksminarayanan R, Bromley KM, Lei YP et al. Perturbed amelogenin secondary structure leads to uncontrolled aggregation in amelogenesis imperfecta mutant proteins. J Biol Chem 2010; 285(52): 40593-40603.
53 Delak K, Harcup C, Lakshminarayanan R et al. The tooth enamel protein, porcine amelogenin, is an intrinsically disordered protein with an extended molecular configuration in the monomeric form. Biochemistry 2009; 48(10): 2272-2281.

(c) SOMERIEHISHESERVEI

This work is licensed under a Creative Commons Attribution-NonCommercial-NoDerivative Works 3.0 Unported License. To view a copy of this license, visit http:// creativecommons.org/licenses/by-nc-nd/3.0

Supplementary Information for this article can be found on Journal of Oral Science's website (http://www.nature.com/ijos). 